\title{
11
}

\section{A violência de gênero no Estado do Rio de Janeiro}

Maria Salet Ferreira Novellino

Filipe Neri Santos ${ }^{* *}$

\section{Resumo}

Nesta pesquisa apresentamos um panorama da violência de gênero no Estado do Rio de Janeiro através da analise de informações contidas nos registros de ocorrência realizados nas Delegacias Civis do Estado do Rio de Janeiro nos anos de 2006 a 2010. Esses dados, cedidos pelo Instituto de Segurança Pública, compreendem exclusivamente os registros de ocorrencia prestados por mulheres em todas as Delegacias Civis do estado, inclusive as Delegacias Especializadas de Atendimento as Mulheres (DEAM). 0 panorama da violência de gênero aqui apresentado, contém os números absolutos de registros para o total do estado, os números relativos para os Municípios, os tipos de violência e de relação dos agressores com as vitimas, bem como características sociodemográficas das mulheres que registraram as ocorrências de violência.

Palavras-chave: Violência de gênero; Violência contra as mulheres; Estudos de gênero

*Doutora em Ciência da Informação pela UFRJ. Pesquisadora Titular e professora da pós-graduação da Escola Nacional de Ciências Estatísticas (ENCE/IBGE).

** Graduando em Estatística da Escola Nacional de Ciências Estatísticas/IBGE e Bolsista PIBIC/CNPq 


\section{Introdução}

0 objetivo desta pesquisa é traçar um panorama da violência de gênero no Estado do Rio de Janeiro através da análise de informações contidas nos registros de ocorrência realizados nas Delegacias Civis do Estado do Rio de Janeiro nos anos de 2006, 2007, 2008, 2009 e 2010. Esses dados, cedidos pelo Instituto de Segurança Pública, compreendem exclusivamente os registros de ocorrência prestados por mulheres em todas as Delegacias Civis do estado, inclusive as Delegacias Especializadas de Atendimento às Mulheres (DEAM).

A violência de gênero compreende a violência cometida contra as mulheres nos espaços privados (violência doméstica) e nos espaços públicos. Tratamos a violência doméstica como violência de gênero, e não como familiar, porque esta expressão subentende que a violência contra a mulher provém de uma relação violenta do casal, em que a mulher pode ser considerada vítima, bem como corresponsável. Na perspectiva da violência de gênero, a violência contra as mulheres é tratada como resultado de uma relação desigual, na qual os homens se acham no direito de cometer atos violentos para subjugar e coagir suas mulheres simplesmente pelo fato de serem homens.

Na teoria feminista, a violência de gênero se explica pelo desequilíbrio de poder entre homens e mulheres, que se configura no controle coercitivo e no terrorismo patriarcal, e é uma ação contínua mais do que um caso episódico, seus efeitos são cumulativos mais do que específicos dos incidentes e o mal que causa pode ser explicado mais por esses fatores do que pelo seu nível de gravidade. (JOHNSON, 1995; STARK, 2007)

0 controle coercitivo compreende violência física, intimidação, isolamento e controle e não se resume a um ato, mas é uma ação contínua e seus perpetradores usam maneiras diversas de ferir, humilhar, intimidar, explorar, isolar e dominar suas vítimas. As vítimas de controle coercitivo podem ser privadas de dinheiro, comida, acesso à comunicação ou transporte, e serem obrigadas a romper relações com familiares e amigos. 0 controle coercitivo é personalizado, estende-se pelo espaço social bem como pelo tempo. É sexualizado porque depende, para o seu impacto, da vulnerabilidade das mulheres devido à desigualdade de gênero (STARK, 2007, p. 241).

Para fazer frente à violência de gênero, primeiramente, foram criados equipamentos para proteger mulheres em situação de violência, como os abrigos. Posteriormente, foram criados mecanismos não só para proteger as mulheres mas também para punir os perpetradores.

No Brasil, contamos com um mecanismo legal que coíbe a prática da violência de gênero e que serve de fundamento para as políticas públicas brasileiras de enfrentamento à violência de gênero. Este mecanismo é a Lei Maria da Penha (Lei Federal $n^{0}$ 11.340/2006). 
Os principais avanços com esta Lei foram: (a) a tipificação da violência doméstica e familiar contra a mulher em física, psicológica, sexual, patrimonial e moral; (b) a criação dos Juizados de Violência Doméstica e Familiar contra a Mulher; (c) a criação de Defensorias Públicas da Mulher; (d) abertura de inquérito policial por depoimentos da vítima, do agressor e de provas documentais e periciais; (e) prisão em flagrante do agressor; (f) medidas protetivas de urgência; $(g)$ inclusão das mulheres em programas oficiais de assistência social; $\mathrm{e}(\mathrm{h})$ atendimento à mulher em situação de violência por serviços articulados em Rede (SPM, 2007, p. 20).

As ações e medidas da Lei Maria da Penha estão organizadas em três eixos: punição, proteção e prevenção e educação. A punição compreende 0 inquérito policial, a aplicação de medidas de prisão em flagrante delito, a proibição de aplicação de penas alternativas, a restrição da representação criminal para determinados delitos e 0 veto à aplicação da Lei $n^{0}$ 9099/1995, que regula a atuação dos Juizados Especiais Criminais, a qualquer crime que se configure como de violência contra a mulher. A proteção compreende a integridade física e os direitos das mulheres bem como medidas de assistência, 0 que faz com que a atenção às mulheres se dê de forma integral, contemplando os atendimentos psicológico, jurídico e social. Prevenção e educação compreendem iniciativas para coibir a reprodução social do comportamento violento e a discriminação de gênero (PASINATO, 2010, p. 14).

0 panorama da violência de gênero aqui apresentado, contém os números absolutos de registros para o total do estado, os números relativos para os Municípios, os tipos de violência e de relação dos agressores com as vítimas, bem como características sociodemográficas das mulheres que registraram a ocorrência de violência.

\section{Os registros de violência no Estado do Rio de Janeiro}

Abaixo apresentamos, em números absolutos, a evolução dos registros ao longo do período considerado.

Do ano de 2006 para 0 ano de 2007, houve um aumento de 6972 registros; de 2007 para 2008 de 2849 registros; de 2008 para 2009 de 10602 registros e de 2009 para 2010 de 3540 registros. Os aumentos nos números de registros podem ser creditados tanto ao crescimento dos casos de violência de gênero quanto ao crescimento das notificações estimuladas pela Lei Maria da Penha. Considerando os dados dos Censos Demográficos 2000 e 2010 para a população feminina do Estado do Rio de Janeiro, a percentagem de mulheres que registraram queixa manteve-se praticamente estável, indo de 1,14\% da população feminina em 2006 para 1,30\% em 2010. 
Tabela 1 Registros de ocorrência

\begin{tabular}{|ccccc|}
\hline 2006 & 2007 & 2008 & 2009 & 2010 \\
\hline 85165 & 92137 & 94986 & 105588 & 109128 \\
\hline
\end{tabular}

Fonte: Instituto de Segurança Pública.

Não podemos afirmar, a partir dos números acima apresentados, que a violência de gênero tenha aumentado ou se mantido estável no Estado do Rio de Janeiro, mas podemos, com os dados contidos nos registros de ocorrência, analisar o fenômeno da violência de gênero e características dos eventos e das pessoas nele envolvidas.

\section{Os tipos de violência contidos nos registros de ocorrência}

Os delitos previstos nos registros de ocorrência são: ameaça, lesão corporal, estupro, tentativa de homicídio, lesão corporal grave, homicídio e atentado ao pudor. Com base nos tipos de violência estabelecidos na Lei Maria da Penha, classificamos estes delitos sob as seguintes categorias: violência psicológica (ameaça), física (lesão corporal, homicídio e tentativa de) e sexual (estupro e atentado ao pudor).

Na Tabela 2 podemos ver a evolução da distribuição dos registros de ocorrência pelos tipos de violência. Os registros denunciando violência física tiveram uma queda de três pontos percentuais e aqueles denunciando violência psicológica aumentaram na mesma medida. Os registros de violência sexual mantiveram-se estáveis no período. A ligeira queda da violência física e a ligeira subida da violência psicológica podem ser creditadas a dois fatores: com a vigência da Lei Maria da Penha, os agressores estariam trocando lesão corporal por ameaça; por outro lado, as mulheres, também a partir da Lei Maria da Penha, teriam aprendido que ameaça, embora não deixe marcas, é um tipo de violência prevista na lei e, portanto, sujeita à punição.

Tabela 2 0s tipos de violência

\begin{tabular}{lccccc}
\hline Tipos de violência & 2006 & 2007 & 2008 & 2009 & 2010 \\
\hline Violência física & 52,53 & 52,67 & 51,20 & 50,53 & 49,24 \\
Violência psicológica & 44,44 & 44,39 & 45,46 & 46,25 & 47,32 \\
\hline Violência sexual & 3,02 & 2,94 & 3,33 & 3,17 & 3,34 \\
\hline
\end{tabular}

Fonte: Instituto de Segurança Pública. 


\section{Quem pratica esses tipos de violência}

Com os dados contidos nos registros de ocorrência, ficamos sabendo quais os tipos de relação dos agressores com as mulheres que registraram ocorrência. Podemos assim determinar quem pratica esses tipos de violência.

A maior parte dos boletins de ocorrência informa que os atuais ou antigos parceiros íntimos são os mais denunciados por agressão. Em seguida, aparecem aqueles que não tinham qualquer relação com a vítima. Esses números indicam que aproximadamente $30 \%$ das agressões foram realizadas por desconhecidos. № entanto, não se deve deixar de considerar a possibilidade de certas mulheres que registraram queixa, por medo ou por escolha, terem resolvido não denunciar agressores com quem tinham algum tipo de relação.

Abaixo vamos cruzar os dados das relações das vítimas com os agressores com os dados dos locais de ocorrência. 0 propósito deste cruzamento é verificar em que locais (residência, local público, via pública) ocorreram os eventos de violência, pressupondo que os eventos com agressores desconhecidos teriam maior chance de ocorrer em local ou via públicos e que nas agressões ocorridas nas residências haveria uma chance maior de 0 agressor ser alguém com relação de intimidade ou familiar com a vítima.

Vamos examinar as distribuições dos tipos de relação de acordo com os locais do evento, concentrando-nos nos casos compreendidos sob os seguintes tipos de relação: nenhuma relação, não especificado e não informado. Tanto nos casos de não especificado como nos de não informado, as maiores proporções estão sob 'residência'. Nos casos sob 'nenhuma relação', mais de $30 \%$ ocorreram em residências. Com esses números podemos arriscar a dizer que as agressões perpetradas por antigos ou atuais parceiros íntimos é ainda maior do que se pode afirmar pelos dados dos registros.

Tabela 3 Tipos de relação das mulheres com os agressores

\begin{tabular}{lccccc}
\hline Tipos de relação & 2006 & 2007 & 2008 & 2009 & 2010 \\
\hline Parceiros íntimos (antigos e atuais) & 35,4 & 37,1 & 38,3 & 39,3 & 34,8 \\
\hline Nenhuma relação & 27,8 & 28,2 & 28,0 & 27,9 & 32,7 \\
\hline Membros da família & 11,6 & 11,5 & 11,5 & 11,4 & 11,1 \\
\hline Pessoas da vizinhança & 10,6 & 10,4 & 9,6 & 9,2 & 9,4 \\
\hline Colegas de trabalho & 1,4 & 1,4 & 1,5 & 1,3 & 1,4 \\
Não especificado & 11,7 & 9,9 & 9,4 & 9,0 & 8,0 \\
Não informado & 1,5 & 1,5 & 1,7 & 2,0 & 2,5
\end{tabular}

Fonte: Instituto de Segurança Pública. 
Tabela 4 Tipos de relação das mulheres com os agressores por local de ocorrência 2010 (\%)

\begin{tabular}{lccccc} 
Relações & Residência & Local público & Via pública & Ignorado & Outros \\
\hline Nenhuma relação & 31,7 & 23,3 & 38,9 & 1,5 & 4,6 \\
\hline $\begin{array}{l}\text { Parceiros íntimos } \\
\text { (antigos e atuais) }\end{array}$ & 72,3 & $5,75 \%$ & 18,3 & 1,9 & 1,7 \\
Membros da família & 81,8 & 3,7 & 11,4 & 1,6 & 1,5 \\
Colegas de trabalho & 18,5 & 63,1 & 11,7 & 1,5 & 5,2 \\
\hline Pessoas da vizinhança & 46,4 & 10,0 & 40,3 & 1,0 & 2,3 \\
Não especificado & 45,5 & 18,1 & 26,8 & 3,5 & 6,1 \\
Não informado & 34,8 & 20,4 & 30,5 & 8,8 & 5,4
\end{tabular}

Fonte: Instituto de Segurança Pública.

\section{Características sociodemográficas das mulheres que registraram ocorrência}

As características sociodemográficas que analisamos são a classe etária, escolaridade e situação conjugal.

Não houve mudanças significativas no que tange às classes etárias no período analisado. Mas identificamos que as mulheres que mais registraram ocorrência estavam na faixa etária entre 18 e 37 anos. Não podemos afirmar que as mulheres nessas classes etárias estariam mais sujeitas a sofrer violência sem verificar a distribuição da população feminina do Estado do Rio de Janeiro por classes etárias. No Gráfico 1, comparamos as distribuições das mulheres que registraram ocorrência de violência com aquelas da população feminina do estado.

Tabela 5 Distribuição das mulheres que registraram ocorrência por classes etárias

\begin{tabular}{lccccc} 
Classes etárias & 2006 & 2007 & 2008 & 2009 & 2010 \\
\hline$\leq 17$ & 9,4 & 9,2 & 9,8 & 9,9 & 10,7 \\
$18-27$ & 31,8 & 31,3 & 30,9 & 30,2 & 29,4 \\
\hline $28-37$ & 28,4 & 28,4 & 28,6 & 28,8 & 29,1 \\
\hline $38-47$ & 17,3 & 17,1 & 16,7 & 16,9 & 16,5 \\
\hline $48-59$ & 8,3 & 8,5 & 8,6 & 9,0 & 9,1 \\
$\geq 60$ & 2,8 & 3,0 & 2,9 & 3,1 & 3,1 \\
Não informado & 2,1 & 2,5 & 2,5 & 2,2 & 2,0
\end{tabular}

Fonte: Instituto de Segurança Pública. 


\section{Gráfico 1 Distribuição das mulheres que registraram ocorrência e da população feminina do Estado do Rio de Janeiro por classes etárias}

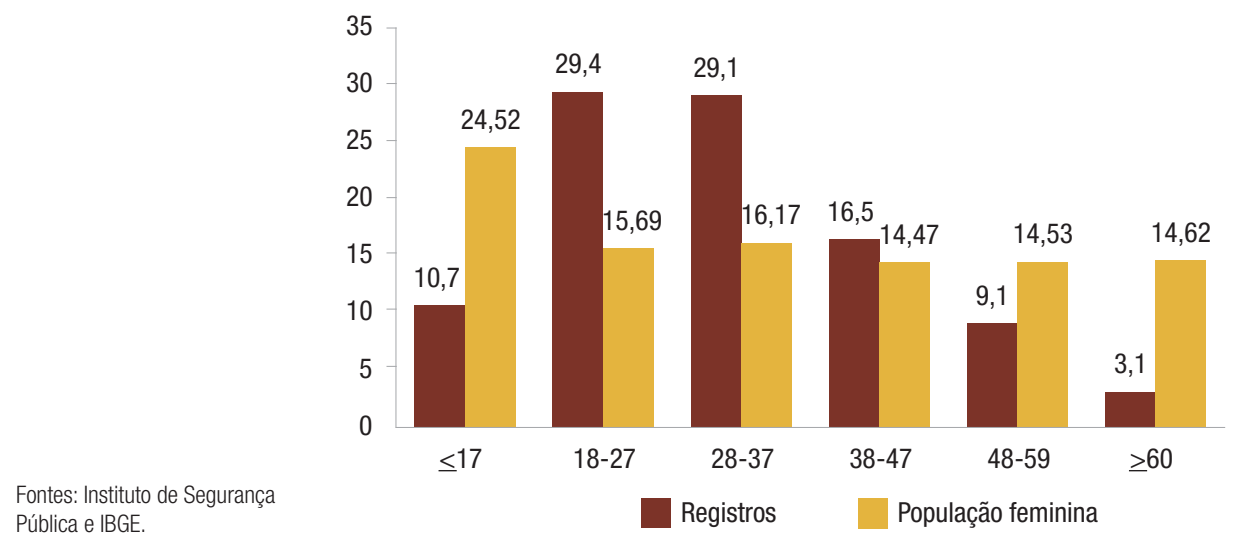

Como podemos ver no Gráfico 1, na faixa etária citada (18 a 37 anos), as proporções de mulheres que registraram eventos de violência cometidos contra elas são superiores às proporções de mulheres nessa mesma faixa no total da população feminina do Estado do Rio de Janeiro. Com base nesses dados, podemos dizer que, de fato, as mulheres entre 18 e 37 anos estão mais sujeitas à violência de gênero.

Os dados sobre grau de instrução e registros de violência mostram que não houve variação significativa no período analisado. Comparamos a distribuição da po-

Tabela 6 Distribuição das mulheres que registraram ocorrência por grau de instrução

\begin{tabular}{lccccc}
\hline Grau de instrução & 2006 & 2007 & 2008 & 2009 & 2010 \\
\hline Analfabeto & 1,10 & 1,06 & 0,99 & 1,02 & 1,03 \\
\hline Alfabetizado & 1,24 & 1,36 & 1,77 & 1,74 & 1,49 \\
\hline $1^{\circ}$ grau incompleto & 29,20 & 26,95 & 26,57 & 27,22 & 27,41 \\
\hline $1^{\circ}$ grau completo & 15,03 & 16,01 & 15,66 & 13,86 & 13,21 \\
\hline $2^{\circ}$ grau incompleto & 9,35 & 8,81 & 8,77 & 9,56 & 9,40 \\
\hline $2^{\circ}$ grau completo & 22,99 & 23,73 & 24,15 & 25,42 & 26,57 \\
\hline $3^{\circ}$ grau completo & 6,49 & 6,72 & 6,67 & 6,87 & 6,84 \\
\hline
\end{tabular}

Fonte: Instituto de Segurança Pública. 
pulação feminina e das mulheres que registraram ocorrência por grau de instrução. Como se pode ver, na Tabela 7, nas classes fundamental completo e médio incompleto, a proporção de vítimas é maior do que a proporção da população indicando que há uma concentração das vítimas com essa classe de instrução.

Na Tabela 8 analisamos a distribuição das mulheres que registraram ocorrência por situação conjugal.

Mais da metade das mulheres que registraram ocorrência eram solteiras. Essas parecem estar mais expostas à violência de gênero do que as casadas.

Em seguida, analisamos a distribuição das vítimas de violência por ocupação.

Mais da metade das mulheres estavam trabalhando à época do registro de ocorrência. Aproximadamente $40 \%$ delas não estavam trabalhando, sendo a maior parte delas donas-de-casa.

Tabela 7 Comparação de grau de escolaridade entre mulheres vítimas de violência e população feminina (\%)

\begin{tabular}{lcc} 
& Mulheres vítimas de violência & População feminina brasileira \\
\hline Sem instrução e fundamental incompleto & 33,0 & 40,0 \\
\hline Fundamental completo e médio incompleto & 25,0 & 17,0 \\
Médio completo e superior incompleto & 35,0 & 31,0 \\
Superior completo & 8,0 & 12,0
\end{tabular}

Fontes: Instituto de Segurança Pública e IBGE.

Tabela 8 Distribuição das mulheres que registraram ocorrência por situação conjugal

\begin{tabular}{lccccc}
\hline Situação conjugal & 2006 & 2007 & 2008 & 2009 & 2010 \\
\hline Solteira & 54,8 & 54,3 & 54,7 & 54,2 & 53,6 \\
\hline Casada & 21,7 & 20,8 & 20,1 & 20,2 & 19,2 \\
\hline Companheira & 8,7 & 9,3 & 10,3 & 11,3 & 12,8 \\
\hline Divorciada & 4,3 & 4,5 & 4,3 & 4,4 & 4,5 \\
\hline Separada & 3,5 & 3,6 & 3,2 & 3,2 & 3,4 \\
\hline Viúva & 3,3 & 3,4 & 3,2 & 3,1 & 3,1 \\
\hline Desquitada & 0,4 & 0,4 & 0,3 & 0,2 & 0,2 \\
\hline Ignorado & 0,3 & 0,3 & 0,3 & 0,5 & 0,8 \\
\hline Não informado & 3,0 & 3,4 & 3,6 & 2,9 & 2,4
\end{tabular}

Fonte: Instituto de Segurança Pública. 
Tabela 9 Distribuição das mulheres que registraram ocorrência por ocupação

\begin{tabular}{lc|}
\hline Ocupadas & 57,0 \\
\hline Dona de casa & 23,8 \\
\hline Estudante & 10,5 \\
\hline Sem trabalho & 4,1 \\
\hline Não informado & 4,6 \\
\hline
\end{tabular}

Fonte: Instituto de Segurança Pública.

\section{Os Municípios do Rio de Janeiro e os registros de violência}

Calculamos a porcentagem de mulheres que registraram ocorrência em 2010 em relação à população feminina de cada Município do Estado do Rio de Janeiro e criamos uma classificação quanto ao nível de violência dos Municípios. Em 19 Municípios $(20,7 \%)$ a violência foi considerada alta, em 31 Municípios $(33,7 \%)$ a violência foi considerada baixa, e em 42 Municípios (45,7\%) a violência foi considerada média.

Na Tabela 10 podemos ver os Municípios com os níveis de violência mais baixos e os mais altos. A cidade do Rio de Janeiro, com a percentagem de 1,14\%, foi classificada como violência de nível médio.

Tabela 10 0s Municípios do Rio de Janeiro com os mais altos e os mais baixos níveis de violência

$\begin{array}{ccc}\text { Quissamã } & 2,77 & \text { alta } \\ \text { Pinheiral } & 2,13 & \text { alta } \\ \text { Rio das Flores } & 2,11 & \text { alta } \\ \text { Queimados } & 2,00 & \text { alta } \\ \text { Bom Jardim } & 0,63 & \text { baixa } \\ \text { Areal } & 0,59 & \text { baixa } \\ \text { Varre-Sai } & 0,55 & \text { baixa } \\ \text { Cardoso Moreira } & 0,43 & \text { baixa }\end{array}$

Fonte: Instituto de Segurança Pública. 


\section{Considerações finais}

Neste artigo, relatamos brevemente uma pesquisa que está sendo realizada com 0 apoio da FAPERJ e com a colaboração do estudante de graduação Filipe Neri Santos com bolsa de iniciação científica outorgada pela ENCE/IBGE. Não podemos deixar de agradecer ao Instituto de Segurança Pública do Estado do Rio de Janeiro, que gentilmente nos cedeu os bancos de dados contendo os registros de ocorrência realizados nas Delegacias Civis de todo o estado.

Neste artigo, traçamos um panorama da violência de gênero no Estado do Rio de Janeiro, esperando colaborar para a compreensão deste fenômeno.

\section{Referências}

BRASIL. SECRETARIA ESPECIAL DE POLITICAS PARA AS MULHERES (SPM).

Enfrentamento à violência contra a mulher: balanço de ações 2006-2007. Brasília, 2007. $61 \mathrm{p}$.

JOHNSON, Michael P. Patriarchal terrorism and common couple violence: two forms of violence against women. Journal of Marriage and the Family, n. 57, p. 283-294, May 1995.

PASINATO, Wânia. Juizados Especiais de Violência Doméstica e Familiar contra a Mulher e a Rede de Serviços para Atendimento de Mulheres em Situação de Violência em Cuiabá, Mato Grosso. Salvador: OBSERVE, 2010. 109 p.

STARK, Evan. Coercive control: the entrapment of women in personal life. New York: Oxford University Press, 2007. $452 \mathrm{p}$. 